This item was submitted to Loughborough's Research Repository by the author.

Items in Figshare are protected by copyright, with all rights reserved, unless otherwise indicated.

\title{
Electro-acoustic crossflow microfiltration
}

PLEASE CITE THE PUBLISHED VERSION

PUBLISHER

(C) Elsevier

VERSION

AM (Accepted Manuscript)

LICENCE

CC BY-NC-ND 4.0

REPOSITORY RECORD

Tarleton, E.S., and Richard J. Wakeman. 2009. "Electro-acoustic Crossflow Microfiltration". figshare. https://hdl.handle.net/2134/5279. 
This item was submitted to Loughborough's Institutional Repository (https://dspace.lboro.ac.uk/) by the author and is made available under the following Creative Commons Licence conditions.

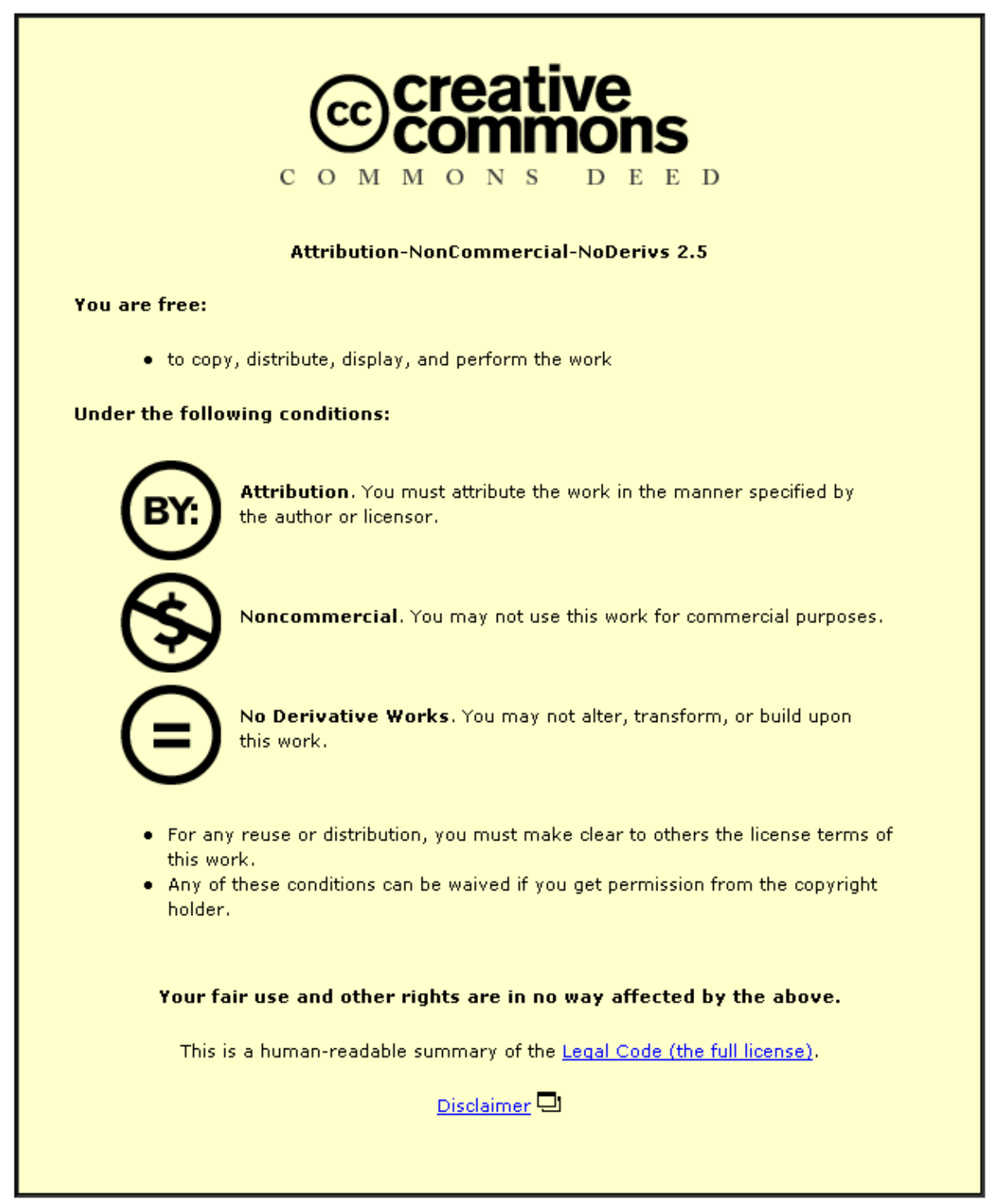

For the full text of this licence, please go to: http://creativecommons.org/licenses/by-nc-nd/2.5/ 


\title{
ELECTRO-ACOUSTIC CROSSFLOW MICROFILTRATION
}

\author{
E.S. Tarleton (e.s.tarleton@lboro.ac.uk) and R.J. Wakeman \\ Separation Processes Centre, University of Exeter, Exeter, Devon, UK.
}

\begin{abstract}
Results from an experimental study of field assisted crossflow microfiltration are presented. It was found that both electric and ultrasonic fields, either in isolation or in combination, can reduce membrane fouling by an amount dependent on the applied field strengths, acoustic frequency, suspension concentration, liquid viscosity, particle size and particle surface charge. Synergistic effects were observed when the fields were applied simultaneously. When force fields are used in microfiltration lower crossflow velocities can be employed. This implies that pumping costs, heat transfer in recirculation loops and the degradation of shear sensitive streams can be substantially reduced.
\end{abstract}

\section{INTRODUCTION}

The use of force fields to aid filtration has attracted an increasing amount of attention in recent years. Magnetically assisted filters are now widely accepted as technical alternatives in the choice of solid/liquid separation equipment and have found many applications, particularly in the mining industries $^{1-3}$. Although electrically assisted filters have been in existence for a longer period of time (since the early part of the $19^{\text {th }}$ century), their industrial application has been more sporadic ${ }^{4-8}$. However, with the advent of membrane technologies, and their associated fouling problems, there has been a resurgence of interest ${ }^{9-12}$. Whilst the properties of ultrasound have been extensively examined by physicists and others and applied to several areas of engineering, its use in filtration studies has been restricted to reports on the (laboratory scale) enhancement of liquid flow through porous media ${ }^{13}$ and sludge dewatering ${ }^{14,15}$. There is a general understanding of the role of magnetic and electric fields in enhanced filtration, but the same cannot be claimed of ultrasonics. This paper is concerned with providing a database of experimental information and an insight into how electric and ultrasonic fields can be used to reduce flux decline in crossflow filters.

\section{EXPERIMENTAL TECHNIQUES}

The experimental programme is divided into two parts. The characterisation tests provided a background knowledge of the properties of the particles, suspensions and membranes used. Such knowledge allowed the interpretation of the membrane fouling phenomena seen in the crossflow microfiltration experiments.

\section{Characterisation Procedures}

The particle size distributions of the three test suspensions (calcite, anatase and china clay powders in distilled water) were evaluated using Malvern Auto- and Master- Sizer instruments and the relationships between $\mathrm{pH}$ and particle surface charge determined using a Malvern Zetasizer. The calcite powder was analar grade supplied by $\mathrm{BDH}$, the anatase was obtained from Tioxide PLC in an uncoated form and the china clay was supplied by ECC International Ltd. These different particle systems were chosen for their variety of size, shape and surface charge characteristics (see Table 1).

The polymeric microfiltration membranes chosen for this study were selected to give septa with differing structures, properties and pore size ratings (see Table 2). Their pore size distributions were measured using a Coulter Porometer and their topographies and cross-sections examined 
using scanning electron microscopy. The latter confirmed the predominantly cylindrical nature and random dispersity of the pores over the surface of the Nuclepore membranes and the microporous structure and pore shape associated with the asymmetric Domnick Hunter Asypor and homogeneous Sartorius membranes respectively.

\section{Microfiltration Experiment Procedures}

The equipment used to assess the effectiveness of electric and ultrasonic fields in microfiltration is shown schematically in Figure 1. The test rig consisted of a recirculation loop around which a suspension of known and essentially constant composition was pumped continuously through a crossflow microfilter at a constant crossflow velocity and trans-membrane pressure. The purpose built microfilter was constructed from plastics and stainless steel (as was the rest of the flow circuit and ancillaries) and comprised a supported $38 \mathrm{~cm}^{2}$ membrane positioned to form one side of a rectangular flow section. The design allowed for the inclusion of mesh electrodes either side of the planar membrane and ultrasound generators in contact with the suspension on the upstream side of the membrane. Several interchangeable filter bodies enabled the distance between the ultrasound source and the membrane to be varied from $15-100 \mathrm{~mm}$ whilst maintaining a fixed $3 \mathrm{~cm}$ gap between the electrodes used to generate the electric field. The ultrasound transducers capable of generating frequencies of $23 \mathrm{kHz}$ and $40 \mathrm{kHz}$ gave nominal power outputs of $3 \mathrm{~W} \mathrm{~cm}^{-2}$ and were mounted such that the generated ultrasound waves travelled through the feed suspension to impinge on any surface foulant or deposit which might accumulate on the membrane. The electric field was applied through the electrodes from a constant voltage DC power supply capable of delivering up to $10 \mathrm{~A}$ at $400 \mathrm{~V}$.

An experimental programme was undertaken such that the matrix of parameters shown in Table 3 were examined in a systematic manner. Prior to the start of a filtration test the suspension was made up to a known concentration and $\mathrm{pH}$ in distilled water, or, with a few experiments, in water and glycerol. The resultant mixture was agitated continuously to maintain an homogeneous mixture and the test performed at the desired filtration conditions for periods up to $2 \mathrm{~h}$. The visually clear filtrates produced were collected via porting behind the membrane with the cumulative volume recorded as a function of time. The filtrate was either returned to the feed tank or discarded, thus both batch and continuous type operations could be evaluated. The temperature of the suspension was maintained at $\sim 25^{\circ} \mathrm{C}$ during each test.

\section{MICROFILTRATION EXPERIMENT RESULTS}

The experimental results from this work are presented in four sections. The first section shows the typical effects of electric fields in crossflow filtration and is intended to compliment the results previously published by the authors. The second section gives information on the effects of an ultrasonic field in the absence of an electric field and the third presents data on the combined effects of electric and ultrasonic fields. The fourth section highlights typical power consumptions for the various modes of operation and shows data which may have considerable industrial significance.

\section{Effects of an Electric Field}

Figure 2 shows the typical influence of a DC electric field gradient on filtrate flux during the crossflow filtration of anatase suspensions. These data show a flux increase of $x 20$ for an applied gradient of $50 \mathrm{~V} \mathrm{~cm}^{-1}$ and illustrate the form of the electrofiltration data measured previously by the authors $^{10,11,16-18}$. The extent of flux improvement was found to be dependent primarily on particle size, surface charge and the magnitude of the imposed field gradient with the power consumed in generating the electric field dependent on the electrode spacing, the applied voltage and the suspension conductivity. Greater flux enhancements are possible for steeper field gradients and finer particles carrying higher surface charges. The mechanisms of enhancement are recognised 
as being due to the electrokinetic phenomena electrophoresis and, to a lesser extent, electroosmosis.

Similar behaviour to that shown on Figure 2 can be demonstrated with a range of solids types such as china clay, bentonite and (ground) calcite, however, of more pertinence here is the use of low crossflow velocities. In field assisted filtrations the high crossflows (of up to $8 \mathrm{~m} \mathrm{~s}^{-1}$ ) seen in industrial microfilters are replaced by a well directed external force field, which utilises an intrinsic property of the feed stream to advantage, and a much lower crossflow (typically $0.1 \mathrm{~m} \mathrm{~s}^{-1}$ ). For electrofiltration this offers potential advantages in terms of reduced pumping costs, less heat input into the process stream and the improved possibilities of processing shear sensitive streams, albeit at the expense of the energy input required to generate the electric field.

\section{Effects of an Ultrasonic Field}

The lack of literature pertaining to the use of ultrasound in crossflow filtration requires the examination of its uses in other areas of processing to identify the possible mechanisms of operation. In many liquids high energy ultrasound (at frequencies in the range $20 \mathrm{kHz}$ to $100 \mathrm{kHz}$ ) produces observable effects such as cavitation, the rapid movement of fluid caused by variations of sonic pressure and microstreaming ${ }^{19}$. The former is manifested as the rapid formation and subsequent violent destruction of gaseous microbubbles at nucleation sites. In a microfilter the nucleation sites can occur on the solids in the feed stream and within both the fouling layers formed on the membrane and the membrane pores themselves. The agitation induced by cavitation close to the membrane is thought to be largely responsible for the effects observed when ultrasound is used to aid microfiltration ${ }^{20-22}$. Parts (a)-(f) describe the influence of a number of parameters on the operation of such systems.

\section{(a) Ultrasonic Frequency}

Figure 3 shows the effect of ultrasonic frequency on filtrate flux. The greater flux improvements with a $23 \mathrm{kHz}$ ultrasound field suggests that cavitation is an important factor. At a frequency of 23 $\mathrm{kHz}$ less sound absorption by the particulate matter in the feed stream occurs with the consequence that a more vigorous 'surface cleaning' action at the membrane can be expected. The cleaning action dislodges the fouling layers formed on the membrane sufficiently to allow the crossflowing stream to, at least, partially remove them. Less flux decline and higher equilibrium fluxes result.

\section{(b) Ultrasonic Field Strength}

The ultrasonic field strength was varied by changing the separation distance between the fixed power ultrasonic source and the membrane surface. Figure 4 shows data where the use of interchangeable filter bodies allowed the separation distance to be either $32 \mathrm{~mm}$ or $100 \mathrm{~mm}$ and produced corresponding ultrasonic power density gradients of 0.8 and $0.26 \mathrm{~W} \mathrm{~cm}^{-2} \mathrm{~cm}^{-1}$ respectively. When the source was brought closer to the membrane, the effect of the ultrasound on improving filtration rates increased considerably due, presumably, to the more vigorous cavitation near the fouling layers on the membrane.

\section{(c) Crossflow Velocity}

The results of a number of tests at crossflow velocities between 0.1 and $2.3 \mathrm{~m} \mathrm{~s}^{-1}$ showed that the improvement in filtrate flux gained by changing velocity alone is often small compared with the potential improvements available from the use of electric or ultrasonic force fields. In fact it has been shown in a separate study of microfiltration (without imposed force fields) that increasing the crossflow velocity does not always lead to an increase in the filtrate flux ${ }^{23}$. Thus, the experiments described in this paper all utilised a crossflow velocity of $0.1 \mathrm{~m} \mathrm{~s}^{-1}$. 


\section{(d) Suspension Concentration}

Increasing the suspension concentration was found to reduce the filtration rate enhancements possible with an ultrasonic field. The fluxes obtained after $4000 \mathrm{~s}$ filtration both with and without an imposed ultrasound field are plotted on Figure 5 as a function of the volume fraction of solids in the feed. At the higher solids concentrations, the ultrasound waves passing through the crossflowing suspension were attenuated to a greater degree (due to the increased acoustic impedance) which resulted in a reduced 'cleaning action' at the membrane surfaces. The degree of attenuation varied with the different feed solids and experimental conditions, and is considered to be an important parameter controlling the efficacy of the ultrasonic field.

\section{(e) Liquid Viscosity}

Several tests were performed with water and water/glycerol mixtures to examine the influence of viscosity. For the experimental conditions used, the attenuation of a $23 \mathrm{kHz}$ ultrasound field was effectively total when the suspension viscosity was raised to $4 \mathrm{cp}$ by the addition of glycerol. Figure 6 shows how the flux improvements (after 60 mins. filtration) obtained by the application of ultrasound were reduced from 0.4 to $0.02 \mathrm{~m}^{3} \mathrm{~m}^{-2} \mathrm{~h}^{-1}$ over the viscosity range $1-4 \mathrm{cp}$.

\section{(f) Particle Size}

The typical influence of particle size is shown on Figure 7, where data for unground (mean size $=8$ $\mu \mathrm{m})$ and wet ground $(3 \mu \mathrm{m})$ calcite suspensions are compared. At the smaller mean particle size the filtration flux is enhanced by ultrasound. Here, the particle movement in the ultrasound field could reasonably be expected to follow more closely that of the suspending fluid with the result that sufficient motion was generated at or near the fouling layer surface to cause the particles to stay in suspension or to re-suspend (with the aid of the crossflow stream). It should be noted that the agitation due to the ultrasound is likely to be complicated by the substantial increase in the number of cavitation nucleation sites generated on the new particle surfaces by the grinding process. When larger particles exist in the feed, ultrasound can lead to a reduced flux rate. Presumably the momentum needed to re-suspend these particles is more than that which can be supplied by the application of the ultrasound and the motion which is imparted to the particles in the fouling layers causes them to 'jostle' and pack more densely.

\section{Effects of Combined Electric and Ultrasonic Fields}

The contributions of each field to a combined field filtration are shown in Figures 8 and 9 . Both electric and ultrasonic fields were seen to reduce fouling when applied individually, but the extent of improvement by the ultrasonic field could be minimal when the feed stream concentration was higher; this is the case on Figures 8 and 9 . The improvement by the electric field was usually greater than that due to the ultrasonic field, particularly when the particles were well dispersed with a high $\zeta$-potential. When the electric and ultrasound fields were applied simultaneously a synergistic interaction occurred whereby flux levels were above those which could be expected from the simple addition of the flux improvements due to the individual fields. The synergy seemed greater with the more problematic suspensions and in particular at higher feed concentrations (for instance the data on Figure 9 were measured for $10.1 \% \mathrm{w} / \mathrm{w}$ anatase suspensions).

In normal crossflow microfiltration (without the addition of imposed force fields) the effect of membrane type appears to be minimal at higher feed concentrations ${ }^{23}$. This is also demonstrated by the bottom two curves on Figure 10 which were obtained using the Nuclepore and Sartorius membranes the characterisation tests showed had markedly different structures. With both membrane types, the filtrate flux was markedly increased by the addition of combined electric and ultrasound fields. The similar fluxes produced indicates that membranes of differing structure should not respond differently in either electric, ultrasonic or combined fields. 


\section{Power Consumptions in Field Assisted Microfiltration}

The experimental data shown in Figures 2-10 have illustrated the large flux increases which are achievable when electric and/or ultrasonic fields are used to aid microfiltration. However, to increase the filtration rate is not necessarily a sufficient criterion by which to assess filter performance. The energy consumed in achieving that rate can be equally as important.

Tables 4 and 5 give a break down of the power consumptions for each of the tests shown in Figures 8 and 9 respectively. The data indicate the contributions to the power consumed by the filter system for the pump used to provide the crossflow, the constant voltage $\left(50 \mathrm{~V} \mathrm{~cm}^{-1}\right)$ D.C. electric field and the $23 \mathrm{kHz}\left(1.7 \mathrm{~W} \mathrm{~cm}^{-2} \mathrm{~cm}^{-1}\right)$ ultrasonic field. The power input figures are quoted per unit membrane area whilst the energy consumed is expressed per unit volume of filtrate. Experiments performed with no imposed force fields employed a crossflow of $2.3 \mathrm{~m} \mathrm{~s}^{-1}$ (for comparison purposes) whereas all the assisted filtrations used the much lower crossflow of $0.1 \mathrm{~m}$ $\mathrm{s}^{-1}$. While the data highlight that actual power inputs with imposed fields were in all cases higher than the corresponding tests with no fields, the energy required to produce a unit volume of filtrate could be decreased significantly for both anatase and china clay suspensions. Moreover, the time taken to extract a unit volume of filtrate from each suspension was reduced with the combined fields by $x 18$ and $x 10$ respectively.

Although the data in Tables 4 and 5 are encouraging they should be viewed in the light that to date little attempt has been made to minimise the power consumed by either the electric or ultrasonic fields. There is probably an optimum balance, which is specific to each filter application, between increasing the rate of separation and the added expenditure on energy required to generate the field(s). In the light of supplementary work carried out alongside this project it is considered that the energy consumed by the electric field could be reduced by 25 to $30 \%$, and that consumed by the ultrasonic field by 50 to $60 \%$. This would reduce power input levels to between one half and two-thirds of those shown on Tables 4 and 5 whilst retaining the filtration rates shown. If this proves possible then field assisted crossflow filtration should compare favourably with conventional crossflow filtration, particularly for difficult-to-filter or 'high value' suspensions.

\section{CONCLUSIONS}

The conclusions to be drawn from this work can be summarised as follows:-

- Both electric and ultrasonic fields can reduce membrane fouling caused by the deposition of colloidal material over a range of operating conditions.

- Flux levels recorded during filtrations assisted by electric and/or ultrasonic fields can be over an order of magnitude higher than corresponding tests with no imposed force fields.

- The rate of fouling in an electro-acoustic filter is affected by parameters such as electric field strength, acoustic field strength and frequency, suspension concentration, particle size, particle shape and the surface properties of the dispersed phase.

- Electric fields enhance filtration by electrophoresis and other secondary electrokinetic effects such as electroosmosis. Ultrasonic fields cause phenomena such as particulate dispersion, viscosity reduction, changes in particle surface properties and cavitation in suspensions. It seems that microfiltration is enhanced with ultrasonic fields largely as a result of cavitation.

- Synergistic effects can be observed when electric and acoustic fields are applied simultaneously during filtration. The coupling mechanism is believed to be due to a combination of effects induced by cavitation and electrokinetic phenomena. 
- Lower crossflow velocities may be employed when combined electric and acoustic fields are used to assist filtration. The crossflow velocity can be an order of magnitude lower than that found in conventional crossflow filtration.

- Using assisted filtration in conjunction with low crossflow velocities offers the potential advantage of reduced pumping costs, lesser degradation of shear sensitive streams and reduced heat transfer requirements in recirculation systems.

\section{REFERENCES}

1. J.H.P. Watson, in Solid-Liquid Separation, $3^{\text {rd }}$ Edn., L. Svarovsky (Ed.), pp.661-684, Butterworths, London, 1990.

2. R.R. Birss and M.R. Parker, in Progress in Filtration and Separation, Vol. 2, R.J. Wakeman (Ed.), pp.171-303, Elsevier, Amsterdam, 1981.

3. B.A. Wills, Mineral Processing Technology, $4^{\text {th }}$ Edn., pp.596-634, Pergamon, Oxford, 1988.

4. H. Beechold, in Colloid Chemistry, Vol. 2, J. Alexander (Ed.), The Chemical Catalog Company, 1926.

5. E. Manegold, Trans. Faraday. Soc., 33, 1088, 1937.

6. A.E. Murphy, Trans. Inst. Rubber Ind., 18, 137, 1942.

7. M.P. Freeman, Paper presented at Orlando '82 AlChE meeting, Orlando, Florida, 28 Feb-3 Mar, 1979.

8. N.C. Lockhart, in Advances in Solid-Liquid Separation, H.S. Muralidhara (Ed.), pp.241-274, Batelle, Ohio, 1986.

9. J.D. Henry, L.F. Lawler and C.H.A. Kuo, AIChEJ, 23(6), 851, 1977.

10. R.J. Wakeman and E.S. Tarleton, Chem. Eng. Sci., 42, 829, 1986.

11. E.S. Tarleton and R.J. Wakeman, Drying Tech., 6(3), 547, 1988.

12. C. Visvanathan and R. Ben Aim, Desalination, 71, 265, 1989.

13. H.V. Fairbanks, Proc. Ultrasonics Symposium, pp.11-15, IPC Science \& Technology Press, Guildford, 1973.

14. H.S. Muralidhara, D. Ensminger and A. Putnam, Drying Tech., 3(4), 529, 1985.

15. H.S. Muralidhara, N. Senapati and R.B. Beard, in Advances in Solid-Liquid Separation, H.S. Muralidhara (Ed.), pp.335-374, Batelle, Ohio, 1986.

16. R.J. Wakeman, Filt. \& Sep., 19(4), 316, 1982.

17. E.S. Tarleton, PhD Thesis, University of Exeter, 1986.

18. R.J. Wakeman and E.S. Tarleton, Filt. \& Sep., 23(3), 174, 1986.

19. F.R. Young, Cavitation, McGraw-Hill, London, 1989. 
20. E.S. Tarleton, Filt. \& Sep., 25(6), 402, 1988.

21. E.S. Tarleton and R.J. Wakeman, Filt. \& Sep., 27(3), 192, 1990.

22. R.J. Wakeman and E.S. Tarleton, Chem. Eng. Res. Des., 69(A5(A)), 386, 1991.

23. E.S. Tarleton and R.J. Wakeman, Proc. FILTECH conference, pp.29-40, The Filtration Society, Karlsruhe, Germany, October 1991.

\section{ACKNOWLEDGEMENTS}

The authors wish to acknowledge receipt of grants from the Specially Promoted Programme in Particulate Technology of The Science and Engineering Research Council in support of this work, and of additional support from the company members of the Separation Processes Centre at Exeter University. 


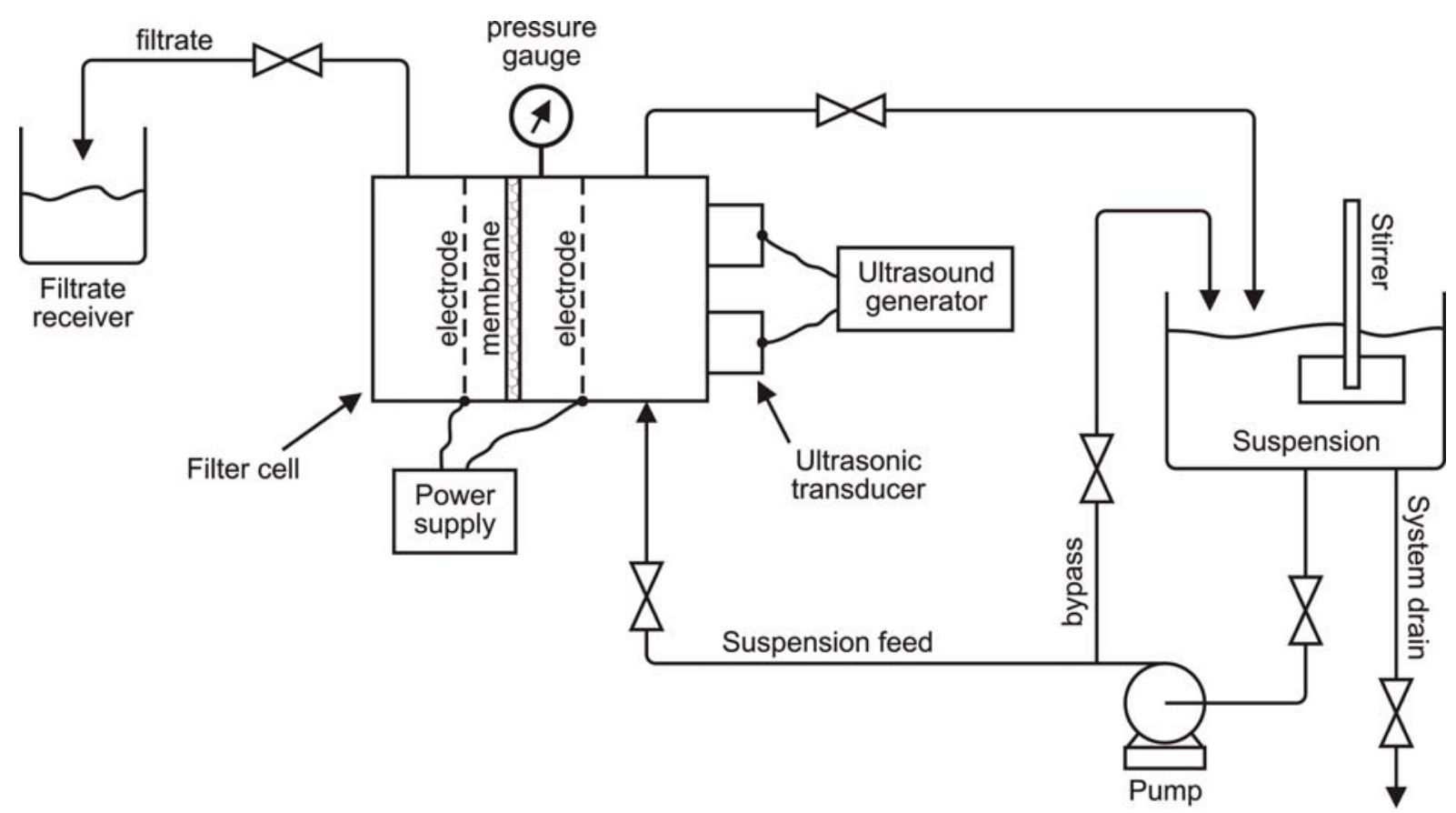

Figure 1. Schematic diagram of the microfiltration cell and flow circuit.

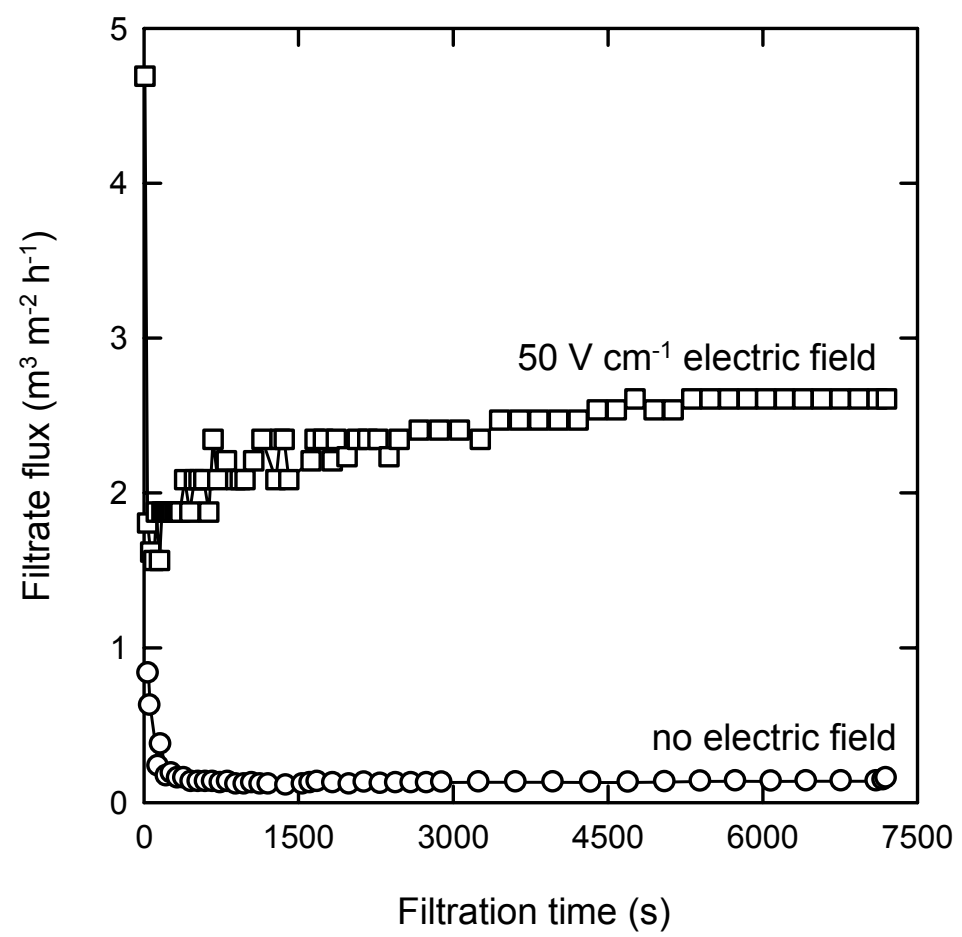

Figure 2. Typical effect of an electric field gradient on the microfiltration of anatase suspensions: no ultrasonic field; solids, anatase; crossflow velocity, $0.1 \mathrm{~m} \mathrm{~s}^{-1}$; filtration pressure, $20 \mathrm{psi}(140 \mathrm{kPa})$; suspension conc., $0.6 \%$ by volume. 


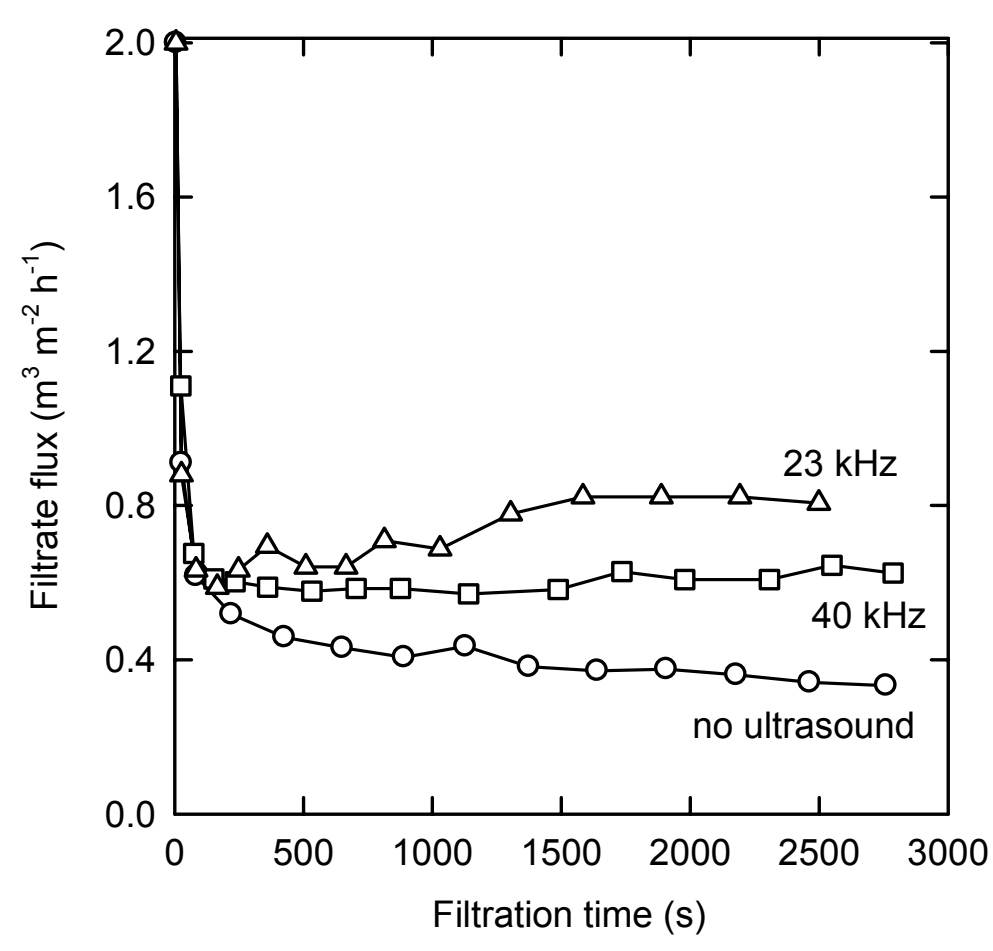

Figure 3. Effect of ultrasound frequency on flux decline for china clay suspensions: ultrasonic density gradient, $1.7 \mathrm{~W} \mathrm{~cm}^{-2} \mathrm{~cm}^{-1}$; no electric field; $\mathrm{pH}, 6.2 ; \zeta,-33 \mathrm{mV}$; suspension concentration, $1.0 \%$ by volume; filtration pressure, $20 \mathrm{psi}$; crossflow velocity, $0.1 \mathrm{~m} \mathrm{~s}^{-1}$.

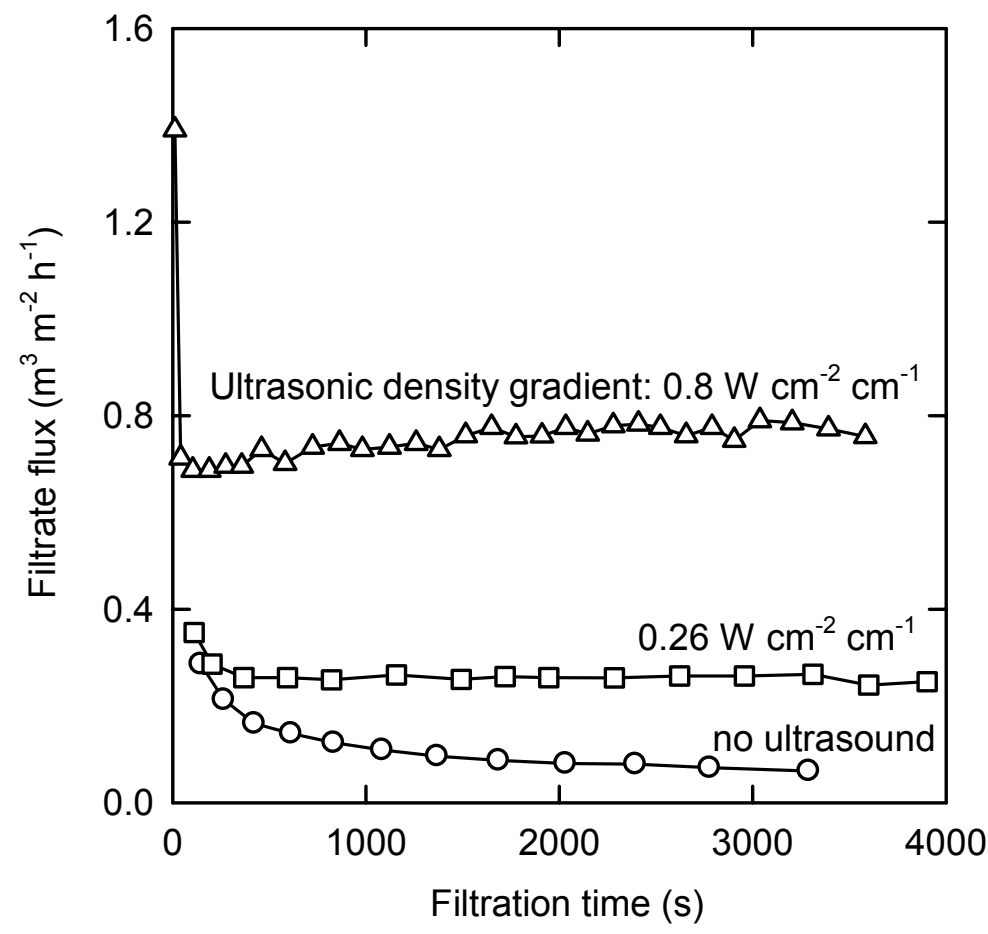

Figure 4. Effect of ultrasonic field gradient on flux decline for anatase suspensions: no electric field; $\mathrm{pH}, 6.6 ; \zeta,-38 \mathrm{mV}$; suspension concentration, $0.67 \%$ by volume; filtration pressure, $20 \mathrm{psi}$; crossflow velocity, $0.1 \mathrm{~m} \mathrm{~s}^{-1}$. 


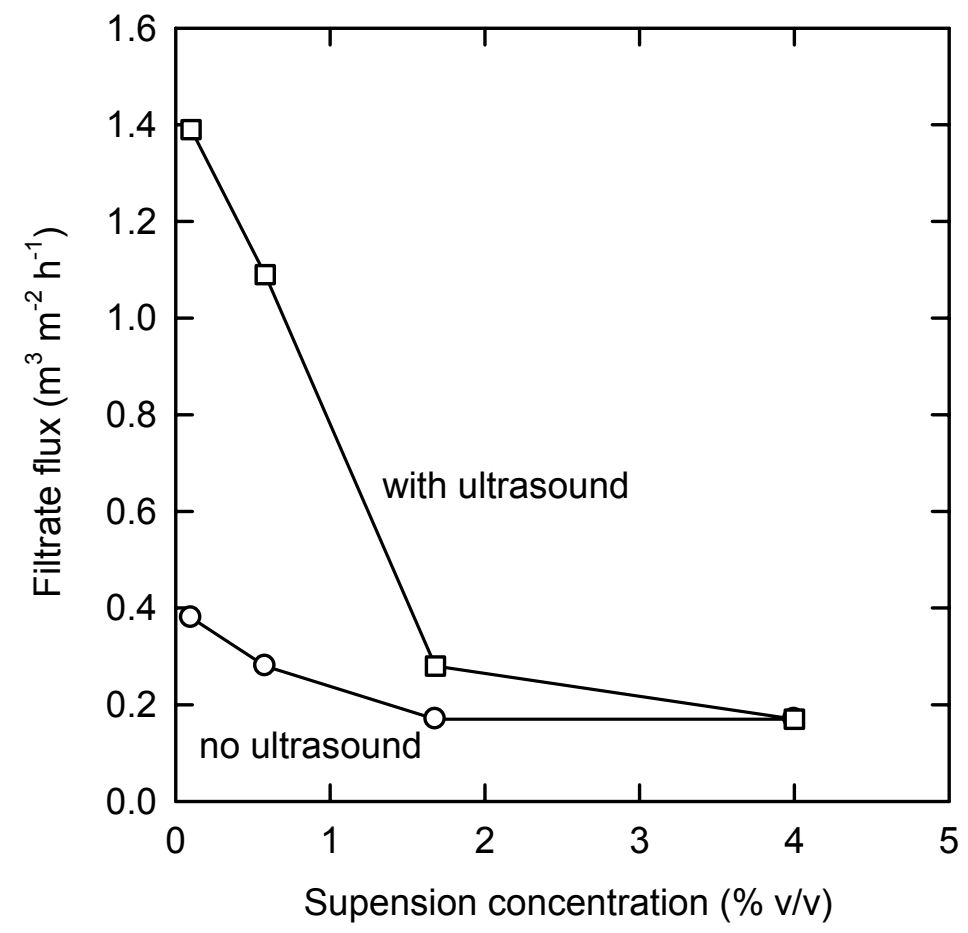

Figure 5. Effect of feed concentration on flux decline for china clay suspensions: no electric field; crossflow velocity, $0.1 \mathrm{~m} \mathrm{~s}^{-1}$; filtration pressure, $20 \mathrm{psi}$; ultrasound frequency, $23 \mathrm{kHz}$.

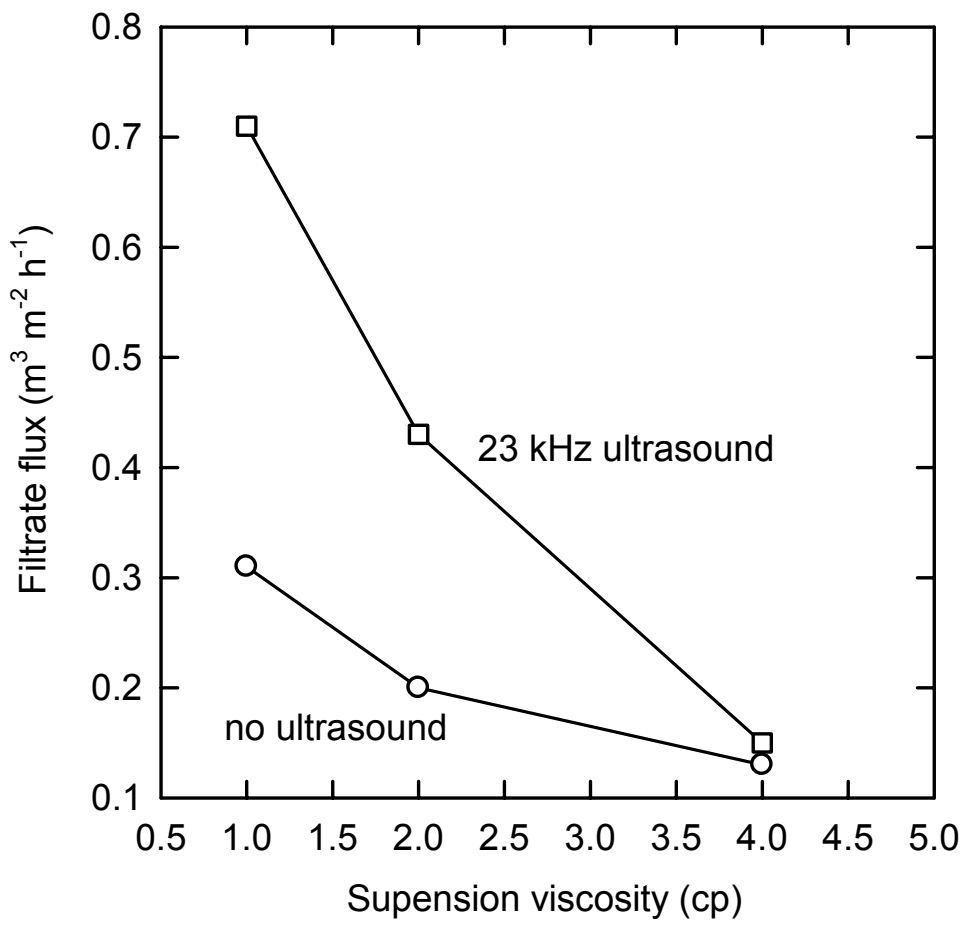

Figure 6. Effect of suspension viscosity on flux decline for china clay suspensions: no electric field; suspension concentration, $1 \%$ by volume; filtration pressure, $20 \mathrm{psi}$; crossflow velocity, $0.1 \mathrm{~m} \mathrm{~s}^{-1}$. 


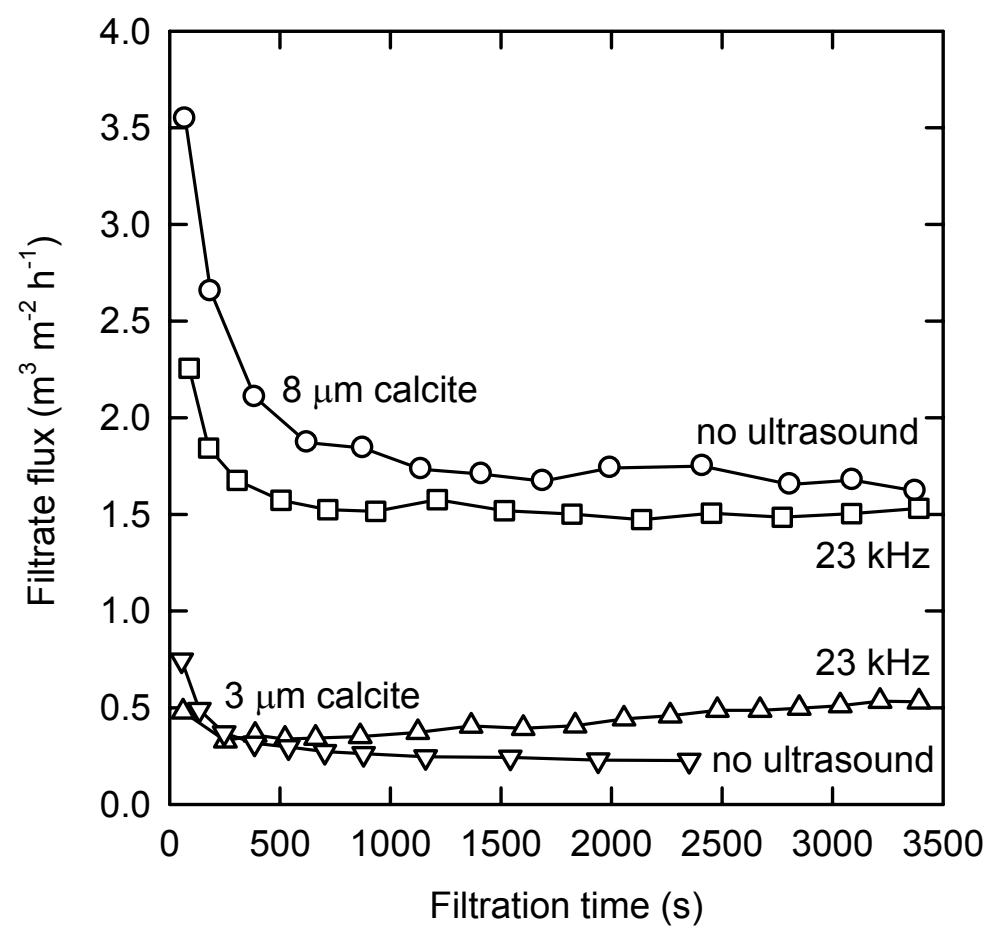

Figure 7. Effect of particle size on flux decline for calcite suspensions: no electric field; ultrasonic density gradient, $1.7 \mathrm{~W} \mathrm{~cm} \mathrm{~cm}^{-1}$; suspension concentration, $2.2 \%$ by volume; $\mathrm{pH}, 10.5 ; \zeta,-20 \mathrm{mV}$; filtration pressure, $20 \mathrm{psi}$; crossflow velocity, $0.1 \mathrm{~m} \mathrm{~s}^{-1}$.

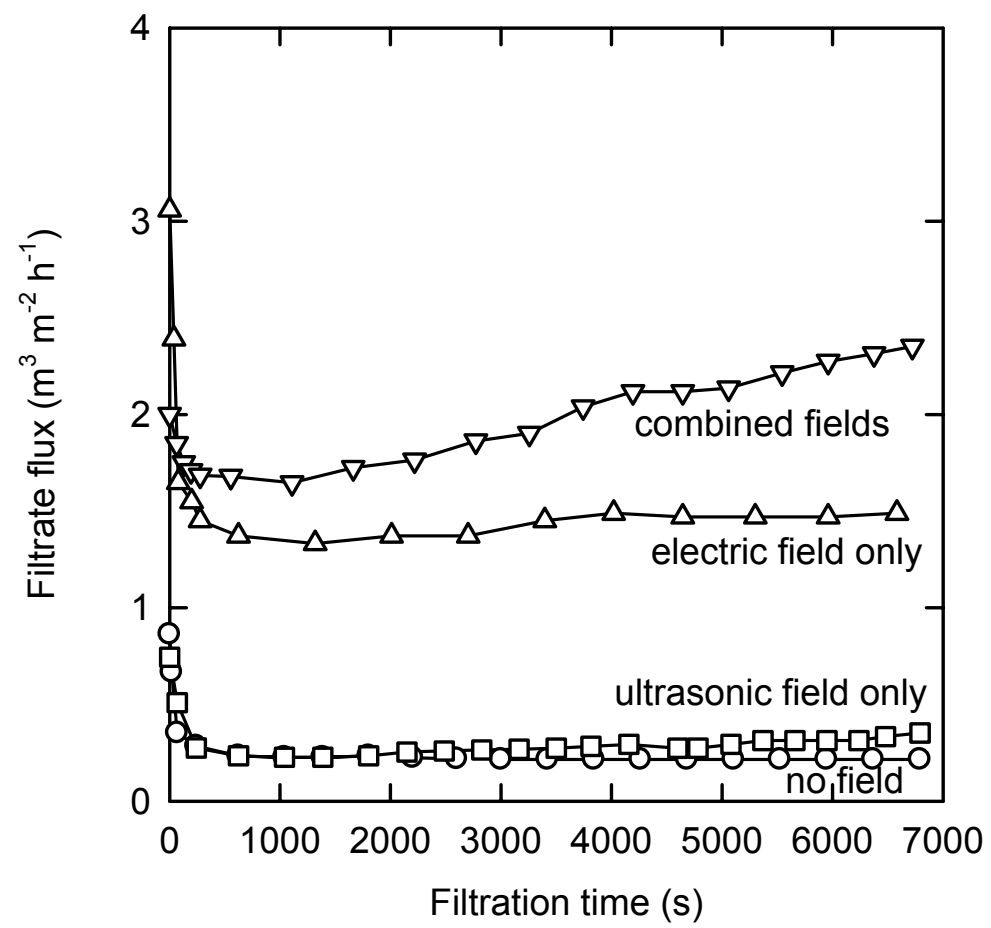

Figure 8. Synergy between electric and ultrasonic fields for china clay suspensions: field gradients, $50 \mathrm{~V} \mathrm{~cm}^{-1}, 1.7 \mathrm{~W} \mathrm{~cm}^{-2} \mathrm{~cm}^{-1}$; suspension concentration, $1.4 \%$ by volume; $\mathrm{pH}, 6.2 ; \zeta,-33 \mathrm{mV}$; filtration pressure, $20 \mathrm{psi}$; crossflow velocity, $0.1 \mathrm{~m} \mathrm{~s}^{-1}$. 


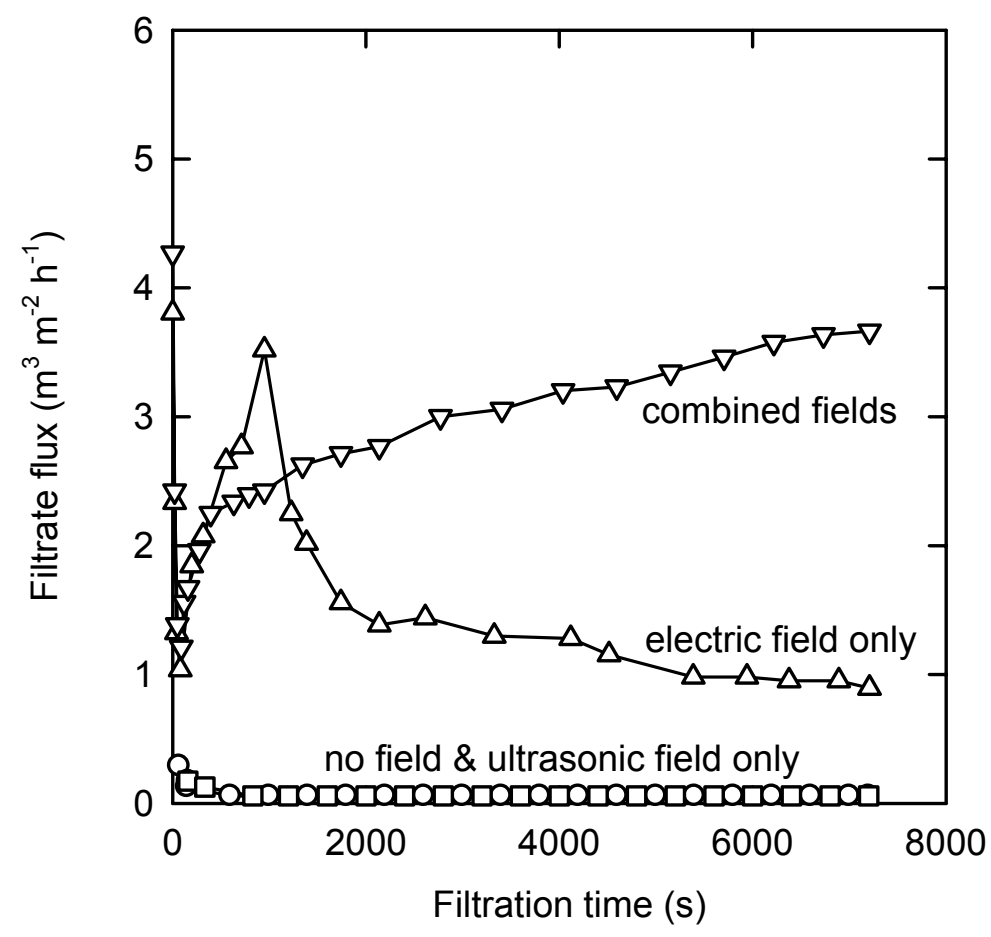

Figure 9. Synergy between electric and ultrasonic fields for anatase suspensions: field gradients, $50 \mathrm{~V} \mathrm{~cm}^{-1}, 1.7 \mathrm{~W} \mathrm{~cm}^{-2} \mathrm{~cm}^{-1}$; suspension concentration, $2.8 \%$ by volume; $\mathrm{pH}, 8.1 ; \zeta,-45 \mathrm{mV}$; filtration pressure, $20 \mathrm{psi}$; crossflow velocity: $0.1 \mathrm{~m} \mathrm{~s}^{-1}$.

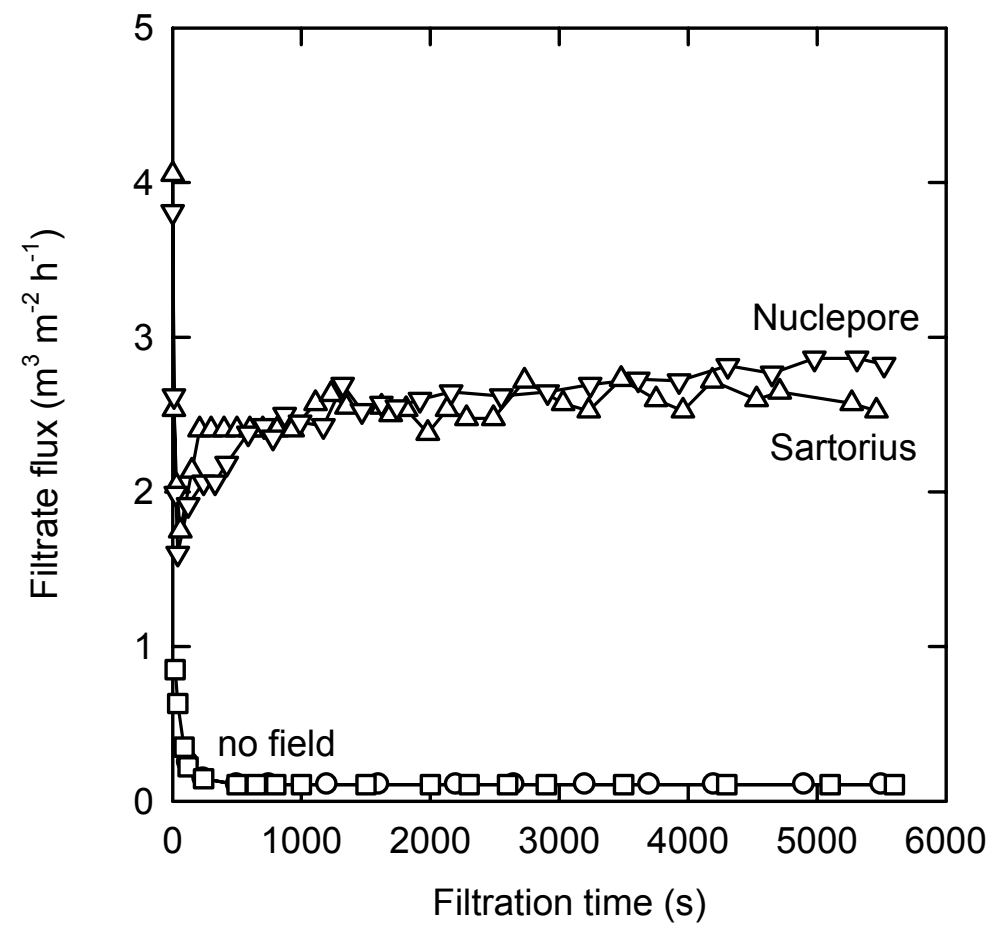

Figure 10. Effect of membrane structure on filtration performance: field gradients, $50 \mathrm{~V} \mathrm{~cm}{ }^{-1}, 1.7 \mathrm{~W}$ $\mathrm{cm}^{-2} \mathrm{~cm}^{-1}$; suspension concentration, $0.7 \%$ by volume; $\mathrm{pH}, 6.8 ; \zeta,-40 \mathrm{mV}$; filtration pressure, 20 psi; crossflow velocity, $0.1 \mathrm{~m} \mathrm{~s}^{-1}$; membrane ratings, $0.2 \mu \mathrm{m}$. 


\begin{tabular}{|c|c|c|c|}
\hline Property & Anatase & Calcite & China clay \\
\hline 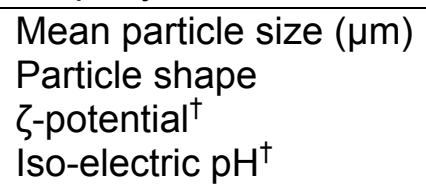 & $\begin{array}{l}0.5 \\
\text { tetragonal } \\
-38 \mathrm{mV} @ \mathrm{pH} 6.6 \\
3.9\end{array}$ & $\begin{array}{l}3 \text { and } 8 \\
\text { rhomboidal } \\
-20 \mathrm{mV} @ \mathrm{pH} 10.5 \\
9.4\end{array}$ & $\begin{array}{l}3.5 \\
\text { platelet } \\
-33 \mathrm{mV} @ \mathrm{pH} 6.2 \\
\sim 1.2\end{array}$ \\
\hline
\end{tabular}

${ }^{\dagger} \mathrm{pH}$ altered with $\mathrm{HCl}$ or $\mathrm{NaOH}$ where necessary

Table 1: Characteristics of the particles and suspensions.

\begin{tabular}{|l|l|l|l|}
\hline Property & Asypor & Sartorius & Nuclepore \\
\hline Polymer type & mixed ester & cellulose nitrate & polycarbonate \\
Structure & microporous, asymmetric & microporous, homogeneous & track etched \\
& pore distribution & 0.2 & \\
Rating $^{\dagger}(\mu \mathrm{m})$ & 0.2 and 0.8 & 0.56 & 0.2 \\
Mean pore size $(\mu \mathrm{m})$ & 0.75 and 1.72 & $0.37-0.71$ & 0.37 \\
Pore size range $(\mu \mathrm{m})$ & $0.5-1.0$ and $1.0-2.31$ & $0.14-0.41$ \\
\hline
\end{tabular}

${ }^{\dagger}$ Manufacturers designation

Table 2: Characteristics of the membranes.

\begin{tabular}{|l|l|l|}
\hline Feed stream & Membrane & Process parameters \\
\hline Particle size & Polymer type & Filtration pressure \\
pH (surface charge) & Structure & Crossflow velocity \\
Solids concentration & Pore size & Electric field strength \\
Liquid viscosity & & Ultrasonic field strength \\
& & Ultrasonic frequency \\
\hline
\end{tabular}

Table 3: Matrix of properties examined in the microfiltration experiments.

\begin{tabular}{|l|c|c|}
\hline Process conditions & $\begin{array}{c}\text { Power inputs to system, pump + } \\
\text { electric + ultrasonic field }\left(\mathrm{kW} \mathrm{m}^{-2}\right)\end{array}$ & $\begin{array}{c}\text { Energy input per unit volume } \\
\text { of filtrate }\left(\mathrm{kWh} \mathrm{m}^{-3}\right)\end{array}$ \\
\hline no fields & $19.6+0+0=19.6$ & 39.3 \\
electric field only & $0.02+9.1+0=9.12$ & 6.1 \\
ultrasonic field only & $0.02+0+24.9=24.92$ & 62.3 \\
combined fields & $0.02+13.0+24.9=37.92$ & 16.5 \\
\hline
\end{tabular}

Table 4: Power consumptions for the microfiltration of $1.4 \% \mathrm{v} / \mathrm{v}$ china clay suspensions. 


\begin{tabular}{|l|c|c|}
\hline Process conditions & $\begin{array}{c}\text { Power inputs to system, pump }+ \\
\text { electric }+ \text { ultrasonic field }\left(\mathrm{kW} \mathrm{m}^{-2}\right)\end{array}$ & $\begin{array}{c}\text { Energy input per unit volume } \\
\text { of filtrate }\left(\mathrm{kWh} \mathrm{m}^{-3}\right)\end{array}$ \\
\hline no fields & $19.6+0+0=19.6$ & 89.1 \\
electric field only & $0.02+93.9+0=93.92$ & 132.3 \\
ultrasonic field only & $0.02+0+24.9=24.92$ & 113.3 \\
combined fields & $0.02+124.7+24.9=149.62$ & 33.9 \\
\hline
\end{tabular}

Table 5: Power consumptions for the microfiltration of $2.8 \% \mathrm{v} / \mathrm{v}$ anatase suspensions. 